\title{
Total synthesis of caulibugulone B
}

\author{
Julio Cesar Milan, Fabrício Fredo Naciuk, and Paulo Miranda \\ Instituto de Química, Universidade Estadual de Campinas, SP \\ *e-mail corresponding author: miranda@iqm.unicamp.br
}

Keywords: Marine isoquinoline alkaloids, Phosphatases inhibitors, Pomeranz-Fritsch reaction

\section{INTRODUCTION}

Caulibugulones (Figure 1) are marine isoquinoline alkaloids with anticancer activity isolated from briozoan Caulibugula intermis. ${ }^{1}$ Among caulibugulones $A-D$, compound $B$ is the most active against CDC25 phosphatases. ${ }^{1}$

There are only two syntheses of this class of compounds and both of them were done at the same year of isolation. ${ }^{2,3}$ Both strategies use the oxidation of a preexistent isoquinoline nucleus as the key-step, and a sequence of amination/ oxidation/halogenation reactions to achieve these compounds. In our work we describe the synthesis of caulibugulone $B$ using Pomeranz-Fritsch cyclization to build the isoquinoline nucleus and a oxidative ether cleavage of the alkoxy groups to give the desired compound.

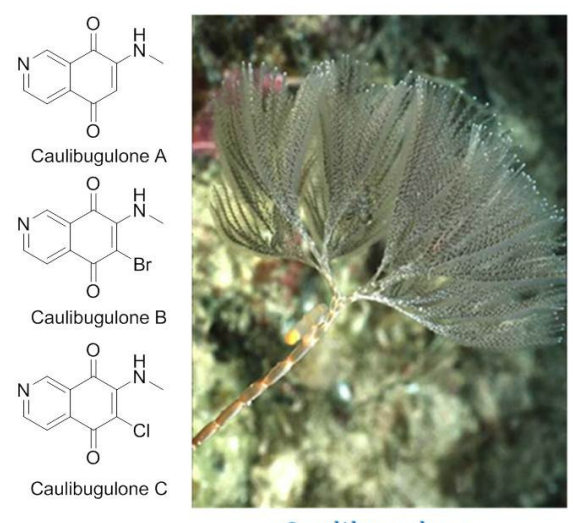

Caulibugulasp.

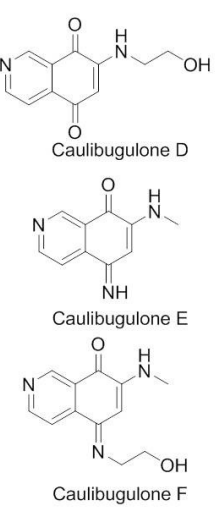

Caulibugulone $\mathrm{F}$
Figure 1. Caulibugula sp and caulibugulones A-F.

\section{RESULTS AND DISCUSSION}

Reductive amination of 2,5-dimethoxybenzaldehyde (2) with 2,2-dimethoxyethanamine () and sodium borohydride furnished the benzylamine $\underline{\mathbf{5}}$ which generated 5,8-dimethoxyisoquiline (므) after Pomeranz-Fritsch based cyclization with heating in trifluoacetic acid (Figure 2).

Oxidative ether cleavage of alkoxy groups in 6 with $\mathrm{N}$-bromosuccinimide in water/tetrahydrofuran ${ }^{4}$ gave dibromoisoquinoline-5,8-dione (ㅍ) which reacted promptly with methylamine in ethanol yielding caulibugulone B (1) (Figure 2).

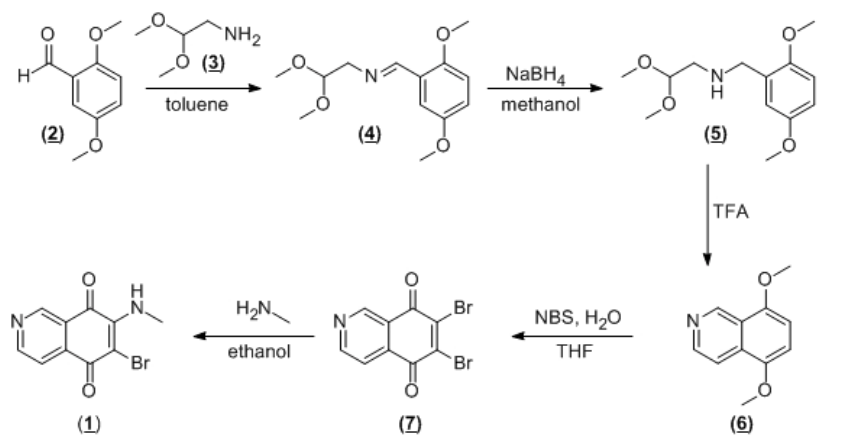

Figure 2. Synthetic route to caulibugulone B.

Our synthetic approach avoid manipulation of the very reactive isoquinoline-5,8-dione since the presence of two halogens at the structure helps its stabilization.

We confirmed the regioselectivity of the nucleophilic displacement of bromine by two dimensional NMR experiments. We also noted that the regioselectivity of this step depend on the media: 5:1 in ethanol to $1: 1$ in chloroform (caulibugulone B:6-bromo-7-(methyl amino)isoquinoline-5,8-dione ratio, respectively).

\section{CONCLUSION}

We developed a new synthesis of caulibugulone $B$ using simple and commercially available starting materials. Our sequence allowed concurrent oxidative ether deprotection and bromination of the isoquinoline nucleus, which suffered aminolysis with methylamine regioselectivilly.

\section{ACKNOWLEDGEMENTS}

The authors acknowledge CNPq and FAPESP 2009/51602-5 for the financial support and IQ-UNICAMP for analytical facilities. JCM and FFN thank CNPq for fellowship.

\section{REFERENCES}

${ }^{1}$ Milanowski, D. J.;Gustafson, K. R.; Kelley, J. A.; McMahon. J. Nat. Prod. 2004, 67, 70.

${ }^{2}$ Alagille, D.; Daldwin, R. M.; Tamagnan, G. D. Tetr Lett, 2004, 45, 6179.

${ }^{3}$ Wipf, P.; Joo, B.; Nguyen, T.; Lazo, J. S. Org. Biomol. Chem. 2004, 2, 2173.

${ }^{4}$ Kim, D. W.; Choi, H. Y.; Lee, K.; Chi, D. Y. .Org. let, 2001, 3, 445. 